Check for updates

Cite this: Mater. Chem. Front. 2019, 3, 1523

Received 26th January 2019, Accepted 10th May 2019

DOI: $10.1039 / c 9 q m 00044 e$

rsc.li/frontiers-materials

\title{
An NIR triphenylamine grafted BODIPY derivative with high photothermal conversion efficiency and singlet oxygen generation for imaging guided phototherapy $\dagger$
}

\author{
Jianwei Zhu, $\neq^{\mathrm{ab}}$ Jianhua Zou, $\ddagger^{\mathrm{b}}$ Zhanjie Zhang, ${ }^{\mathrm{a}}$ Jie Zhang, ${ }^{\mathrm{a}}$ Yang Sun, ${ }^{\mathrm{a}}$ \\ Xiaochen Dong*b and Qi Zhang (D)*a
}

\begin{abstract}
Osteosarcoma, the most common malignant bone tissue tumor, with a high degree of malignancy, strong metastasis, and early lung metastasis, can result in extremely high mortality, and is a serious threat to human health. Boron dipyrromethene (BODIPY) compounds have shown great potential in photodynamic tumor therapy. In this study, an NIR triphenylamine grafted BODIPY derivative (BDPTPA) with high singlet oxygen generation efficiency (35.2\%) was designed and synthesized. BDPTPA nanoparticles (NPs) obtained by nanoprecipitation present high photothermal conversion efficiency (52.6\%). Both MTT assay and flow cytometry experiments suggest that BDPTPA NPs are able to generate high photo-toxicity and induce apoptosis of osteosarcoma cells, while presenting negligible dark-toxicity towards osteosarcoma cells as well as normal human cells. Cell migration and transwell experiments demonstrate that BDPTPA NPs can inhibit the migration of osteosarcoma cells. Due to the enhanced permeability and retention (EPR) effects, BDPTPA NPs can accumulate in tumor tissue in $6 \mathrm{~h}$. Pharmacokinetic studies in rats indicate that BDPTPA NPs eliminate much more slowly than BDPTPA in $10 \%$ DMSO. Under the irradiation of an $808 \mathrm{~nm}$ laser, in in vivo experiments, BDPTPA NPs can significantly inhibit tumor growth without side effects towards normal tissues. BDPTPA NPs show good biosafety and excellent therapeutic effect both in vitro and in vivo, indicating their great potential for treatment of osteosarcoma.
\end{abstract}

\section{Introduction}

Osteosarcoma, including primary bone tumors and metastatic bone tumors, ${ }^{1}$ accounts for about $1 \%$ of all malignant tumors. ${ }^{2}$ Osteosarcoma is the most common tumor that occurs in children and young adults, and has a high rate of death and disability, and its current five-year survival rate is about $65-75 \% .^{3-7}$ The diagnosis and treatment of osteosarcoma is still a difficult problem because the location of the tumor is deep in the bone tissue. ${ }^{8}$

At present, surgery and chemotherapy play significant and crucial roles in clinical osteosarcoma treatment. ${ }^{9}$ Although the

\footnotetext{
${ }^{a}$ School of Pharmaceutical Sciences, Nanjing Tech University (NanjingTech), 30 South Puzhu Road, Nanjing 211816, China. E-mail: zhangqi@njtech.edu.cn

${ }^{b}$ Key Laboratory of Flexible Electronics (KLOFE) \& Institute of Advanced Materials (IAM), Jiangsu National Synergetic Innovation Centre for Advanced Materials (SICAM), Nanjing Tech University (NanjingTech), 30 South Puzhu Road,

Nanjing 211816, China. E-mail: iamxcdong@njtech.edu.cn

$\dagger$ Electronic supplementary information (ESI) available. See DOI: 10.1039/ c9qm00044e

\$ These authors contribute equally to this work.
}

principle of surgery is to remove the tumor as completely as possible, osteosarcoma often has invasive growth, close adhesion to surrounding tissues, and strong recurrence, leading to difficulty in removing the tumor tissue completely. ${ }^{10}$ Surgery usually combines radiotherapy, ${ }^{11,12}$ chemotherapy ${ }^{13,14}$ and immunotherapy, ${ }^{15,16}$ but surgical resection can damage the function of the limb and most osteosarcoma is insensitive to radiotherapy, and there are many defects in chemotherapy. Currently, there are no specific drugs for treating osteosarcoma and traditional drugs usually causes severe toxicity and side effects, even multiple resistance. In addition, due to poor permeability of bone tissue, drug accumulating in bone tumors by traditional administration methods is far from satisfactory. Based on these observations, it is urgent to explore and discover effective treatment methods for such a common and serious disease.

Phototherapy, including photodynamic therapy and photothermal therapy, is a minimally invasive technique for tumor treatment. ${ }^{17-19}$ Compared with traditional treatment methods, phototherapy has the following advantages: ${ }^{20-23}$ (1) universal applicability: it has a therapeutic effect on a variety of tumors, 
and after long-term follow-up and evaluation, it will not produce drug resistance; (2) targeting: it only acts on a specific tumor site, and the laser is only irradiated on the tumor tissue containing the photosensitizer, and does not cause damage to normal tissues; (3) minimally invasive: it only produces a killing effect on local tumors, and does not cause much damage to surrounding normal tissues and the whole body. By injecting a photosensitizer, a specific wavelength of visible light is used to locally irradiate the tumor area. Photochemical and photobiological reactions produce high levels of reactive oxygen species (ROS), ${ }^{24,25}$ which will induce apoptosis and necrosis at the site of the lesion. ${ }^{26,27}$ While photothermal therapy is a therapeutic strategy in which photon energy is converted into heat to burn tumor cells to death, it also causes vascular damage, and microcirculatory disorders, and affects tumor blood supply. ${ }^{28-30}$ From the view of synergistic therapy, combining PDT with photothermal therapy (PTT) ${ }^{31-33}$ is a wise strategy for treatment of cancer. Nanomaterial-based PDT/PTT therapy is considered to be a promising treatment for bone tumors because of its specific killing and controllability in time and space.

Currently, the research progress of phototherapy in the treatment of osteosarcoma is relatively limited. The commonly used photosensitizers are also limited to acridine orange, ${ }^{34,35}$ 5-aminolevulinic acid, ${ }^{36,37}$ mesotetrahydroxyphenylchlorin (mTHPC), ${ }^{38}$ hiporfin, ${ }^{39}$ methylene blue ${ }^{40}$ and so on. But these photosensitizers have many drawbacks, such as poor biosecurity, obvious side effects, low efficiency and poor penetration. Therefore, there is an urgent need to develop new photosensitizers that can inhibit the proliferation of osteosarcoma. BODIPY (boron-dipyrromethene) ${ }^{41-46}$ derivatives are potential candidates for imaging guided phototherapy. In this study, we have designed and synthesized a new compound 10-(5-bromothiophen-2-yl)-3,7-bis((E)-4-(diphenylamino)styryl)-5,5-difluoro1,9-dimethyl-5H-dipyrrolo[1,2-c:2 $\left.2^{\prime}, 1^{\prime}-f\right][1,3,2]$ diazaborinin-4-ium5-uide (BDPTPA), which has both photothermal and photodynamic effects. The singlet oxygen yield and photothermal conversion efficiency of BDPTPA were as high as $35.2 \%$ and $52.6 \%$, respectively. By nanoprecipitation, soluble and stable BDPTPA NPs can be obtained and it has a wide absorption range which extends to the near-infrared region (600-1100 nm), showing a better ability to penetrate biological tissues. At the same time, the NPs can acquire passive targeting ability, which makes it easier for them to accumulate in the tumor tissue due the enhanced permeability and retention effect (EPR), and the in vivo fluorescence imaging illustrates this point. In vitro cell experiments proved that BDPTPA NPs have an excellent photo toxicity which can induce apoptosis of osteosarcoma cells, while good biological safety and little adverse effect on the viability of normal cells. Furthermore, in vivo experiments indicate that BDPTPA NPs also inhibit tumor growth in nude mice even without any side effects. Moreover, the pharmacokinetic studies reveal the process of absorption and distribution of drugs in rats, and the terminal elimination half-lifes $\left(T_{1 / 2}\right)$ of BDPTPA and BDPTPA NPs were $1.727 \pm 0.415$ and $5.639 \pm 0.37 \mathrm{~h}$, respectively, which also prove that BDPTPA NPs could be more suitable for treatment. Our results indicate that

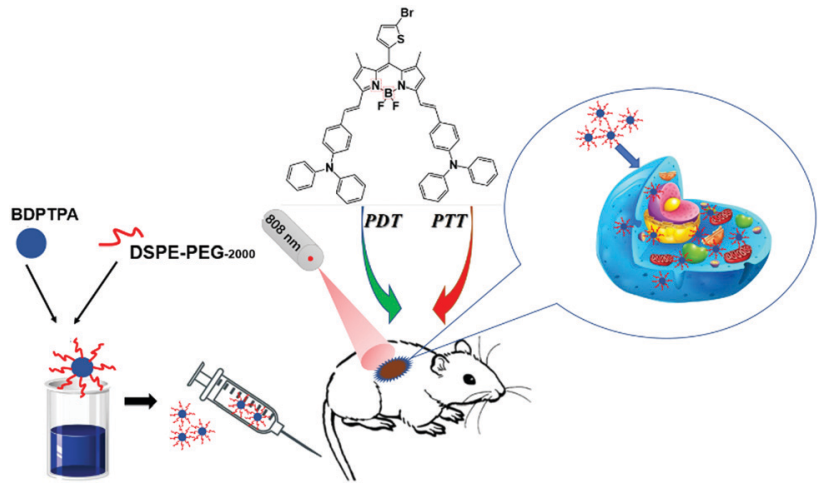

Scheme 1 Illustration of BDPTPA NPs for PDT/PTT synergistic therapy.

BDPTPA NPs are potential candidate for imaging guided phototherapy in the clinic (Scheme 1).

\section{Experimental}

\section{Materials and reagents}

All the chemicals were purchased from Sigma-Aldrich. The ${ }^{1} \mathrm{H}$ NMR and ${ }^{13} \mathrm{C}$ NMR spectra were recorded in $\mathrm{CDCl}_{3}$ solution on a Bruker DRX NMR spectrometer (500 MHz) with solvent residual as the internal standard. The UV-vis spectra were measured on a spectrophotometer (UV-3600, Shimadzu, Japan). The fluorescence spectra were recorded on a spectrometer (F-4600, HITACHI, Japan). The size of the nanoparticles was recorded by a particle size analyzer (90 Plus, Brookhaven Instruments, USA). The morphology of the nanoparticles was determined on a transmission electron microscope (JEM-2100, JEOL). The bio-images of the tumor, heart, liver, spleen, lung and kidneys were recorded on an imaging system (IVIS Lumina K, PerkinElmer).

\section{Synthesis of BDPTPA}

A mixture of 10-(5-bromothiophen-2-yl)-5,5-difluoro-1,3,7,9-tetramethyl-5H-dipyrrolo[1,2-c: $\left.2^{\prime}, 1^{\prime}-f\right][1,3,2]$ diazaborinin-4-ium-5-uide $(0.409 \mathrm{~g}, 0.001 \mathrm{~mol})$ and 4 -(diphenylamino)benzaldehyde $(0.820 \mathrm{~g}$, $0.003 \mathrm{~mol}$ ) was dissolved in DMF, which was heated at $120{ }^{\circ} \mathrm{C}$ using acetic acid $(0.4 \mathrm{~mL})$ and piperidine $(0.4 \mathrm{~mL})$ as a catalyst. Then the mixture was poured into brine, extracted with $\mathrm{CH}_{2} \mathrm{Cl}_{2}$ three times $(10 \mathrm{~mL})$, then washed with brine and dried with anhydrous sodium sulfate. The solvent was removed by rotary evaporation, and the crude product was purified by column chromatography (silica gel, DCM $: \mathrm{PE}=1: 2, \mathrm{v} / \mathrm{v}$ ).

\section{Preparation of nanoparticles of BDPTPA}

The nanoparticles of the compound were prepared by nanoprecipitation. In brief, a mixture of BDPTPA $(10 \mathrm{mg})$ and DSPE-PEG $_{-2000}(2 \mathrm{mg})$ was dissolved in tetrahydrofuran $(1 \mathrm{~mL})$. Then $200 \mu \mathrm{L}$ of the solution was added into $10 \mathrm{~mL}$ of water under ultrasound at room temperature. The mixture was stirred for another $20 \mathrm{~min}$ to remove the tetrahydrofuran by nitrogen blowing. BDPTPA NPs in the solution were obtained by centrifugation. 


\section{Singlet oxygen detection in DCM and water}

The singlet oxygen generation of BDPTPA was detected with 1,3-diphenylisobenzofuran (DPBF) which was used as a singlet oxygen detector. Briefly, $20 \mathrm{mM}$ DPBF was added to the BDPTPA solution in a dark room. Then the mixture was irradiated using laser irradiation $\left(808 \mathrm{~nm}, 1.0 \mathrm{~W} \mathrm{~cm}^{-2}\right)$. Methylene blue is used as a standard substance to calculate the singlet oxygen quantum yield of BDPTPA. SOSG (singlet oxygen sensor green) was used to detect the singlet oxygen generation of BDPTPA NPs. The fluorescence intensity of SOSG was recorded after irradiation at $492 \mathrm{~nm}$.

\section{Cell culture}

The human osteosarcoma cell lines used in this study were obtained from Cell Bank of Shanghai Institute of Biochemistry and Cell Biology, Chinese Academy of Sciences. The MG-63 and HOS cells were cultured in Minimum essential medium (Gibco; Thermo Fisher Scientific) with 10\% fetal bovine serum (FBS; Gibco; Thermo Fisher Scientific), and the U2OS and Saos-2 cells were cultured in McCoy's 5A (Modified) Medium (Thermo Fisher Scientific, Waltham, MA, USA) with $15 \%$ fetal FBS. The 143B and L02 cells were cultured in RPMI-1640 (Gibco; Thermo Fisher Scientific) with $10 \%$ fetal bovine serum, and the HEK293, HUVEC and BEAS-2B cells were cultured in Dulbecco's minimum essential medium (Gibco; Thermo Fisher Scientific) with $10 \%$ FBS, and all of the complete culture media contain 100 units per $\mathrm{mL}$ penicillin and $100 \mu \mathrm{g}$ per mL streptomycin. All the cells were cultured at $37{ }^{\circ} \mathrm{C}$ in a humidified incubator with $5 \% \mathrm{CO}_{2}$.

\section{MTT assay}

Cell viability of the nanoparticles was determined using a 3-(4,5-dimethylthiazol-2-yl)-2,5-diphenyltetrazolium bromide (MTT) colorimetric assay. Cells were seeded into 96-well plates with $1 \times 10^{4}$ per well in $100 \mu \mathrm{L}$ culture medium. The cells were incubated for $24 \mathrm{~h}$ and then exposed to drug at various concentrations, and the control cells were treated with $0.5 \%$ DMSO. Then the 96-well plate was irradiated with a laser ( $808 \mathrm{~nm}, 0.5 \mathrm{~W} \mathrm{~cm}^{-2}$ ) for 8 minutes. After that, the cells were still incubated for another $12 \mathrm{~h}$. Subsequently, $10 \mu \mathrm{L}$ MTT solution (5 mg mL $\mathrm{mL}^{-1}$ in PBS) was added and incubated for $4 \mathrm{~h}$, Then the supernatants were removed and $100 \mu \mathrm{L}$ DMSO was added to dissolve the formazan crystals. The absorbance was recorded at $492 \mathrm{~nm}$ by a Thermo Multiskan Mk3 Microplate Reader at ambient temperature. The cell viability was calculated by the following equation: cell viability $(\%)=$ $\left(A_{\text {treatment }} / A_{\text {control }}\right) \times 100 \%$ (mean absorbance in each group incubated with different concentrations of NPs/mean absorbance in the control group). The half-maximal inhibitory concentration $\left(\mathrm{IC}_{50}\right)$ was determined using GraphPad Prism 6 software (GraphPad Software, Inc., La Jolla, CA, USA).

\section{Cellular uptake study}

143B cells were incubated with BDPTPA NPs $\left(1 \mu \mathrm{g} \mathrm{mL}{ }^{-1}, 2 \mathrm{~mL}\right)$ in a confocal dish for $24 \mathrm{~h}$ in a $5 \% \mathrm{CO}_{2}$ incubator. Then the medium was removed and the cells were washed with PBS, followed by the addition of $1 \mathrm{~mL} \mathrm{70 \%} \mathrm{ethyl} \mathrm{alcohol} \mathrm{for} 15 \mathrm{~min}$ at $4{ }^{\circ} \mathrm{C}$. Then ethyl alcohol was discarded and the cells were washed with PBS three times. The fluorescence images are observed with an Olympus IX 70 inverted microscope excited with a $633 \mathrm{~nm}$ laser and collected from 650 to $750 \mathrm{~nm}$.

\section{Fluorescence imaging of cellular ROS}

143B cells were seeded into a confocal dish and incubated with culture media at $37{ }^{\circ} \mathrm{C}$ for 24 hours in a $5 \% \mathrm{CO}_{2}$ incubator, followed by incubation with the media containing BDPTPA NPs (5 $\mathrm{g} \mathrm{g} \mathrm{mL}{ }^{-1}, 1 \mathrm{~mL}$ ) for an additional $24 \mathrm{~h}$. Then, the cells were incubated with 2,7-dichlorodihydrofluorescein diacetate (DCFH-DA, $1 \mu \mathrm{g} \mathrm{mL} \mathrm{m}^{-1}, 2 \mathrm{~mL}$ ) for $20 \mathrm{~min}$. Then the cells were washed with PBS three times and irradiated with a laser ( $808 \mathrm{~nm}, 0.5 \mathrm{~W} \mathrm{~cm}^{-2}$ ) for $10 \mathrm{~min}$. The fluorescence images are observed by an Olympus IX 70 inverted microscope excited at $488 \mathrm{~nm}$ and collected from 500 to $600 \mathrm{~nm}$ for DCF detection.

\section{Cell wound healing assay}

143B cells were seeded into a 6-well culture plate with CultureInserts (IBIDI, German) in each well and incubated with culture media at $37{ }^{\circ} \mathrm{C}$ for 24 hours in a $5 \% \mathrm{CO}_{2}$ incubator. All cells were set up into three groups including control, illumination and without illumination groups. And then, cells in the illumination group were treated with the BDPTPA NPs $\left(1 \mu \mathrm{g} \mathrm{mL} L^{-1}\right)$ and irradiated with a laser for $5 \min \left(808 \mathrm{~nm}, 0.5 \mathrm{~cm}^{-2}\right)$; without illumination group cells were only treated with BDPTAPA NPs at the same concentration while control group cells were incubated with fresh media. $12 \mathrm{~h}$ later, a cell-free gap of $500 \mu \mathrm{m}$ was created after removing the Culture-Inserts, and cells in the three groups were allowed to migrate into the wound area. Images were captured using a Nikon Inverted Microscope (Nikon TS100, Nikon, Tokyo, Japan).

\section{Transwell invasion assay}

Cell invasion assays were evaluated in Transwell 24-well Boyden chambers $(8.0 \mu \mathrm{m}$ pore; BD Biosciences) precoated with $20 \mu \mathrm{g}$ Matrigel (BD Bioscience) in a complete medium, and the group setting was the same as in the cell wound healing assay. Approximately $2 \times 10^{4}$ cells per mL 143B cells were plated in the top chamber with serum-free medium containing BDPTPA NPs, while the culture medium with $10 \%$ FBS was added to the bottom chamber; after that the cells were irradiated with a laser for $5 \mathrm{~min}\left(808 \mathrm{~nm}, 0.5 \mathrm{~W} \mathrm{~cm}^{-2}\right)$ and incubated at $37{ }^{\circ} \mathrm{C}$ for 24 hours. After treatment, the invaded cells were fixed and stained, photographed and counted under a microscope (Nikon TS100, Nikon, Tokyo, Japan).

\section{Antitumor effects in nude mice of xenograft tumor models}

28-35 day old male BALB/c nude mice, weighing $20 \pm 2$ g, were obtained from the Comparative Medicine Centre of Yangzhou University. The animal study was carried out according to the National Institutes of Health regulations and approved by the Institutional Animal Care and Use Committee. The 143B cells were injected subcutaneously into the nude mice at a density of 
$5 \times 10^{6}$ cells per $100 \mu \mathrm{L}$ serum free medium, and the tumor size was measured every two days. When the tumor volume reaches about $100 \mathrm{~mm}^{3}$, the mice were randomly divided into three groups: (i) a control group with tail vein injection of saline solution; (ii) an illumination group with injection of BDPTPA NPs and under irradiation; (iii) a without illumination group with intravenous injection of BDPTPA NPs without irradiation. $10 \mu \mathrm{g}\left(100 \mu \mathrm{g} \mathrm{mL} \mathrm{m}^{-1}, 100 \mu \mathrm{L}\right)$ BDPTPA NPs were injected into such mice via the tail vein for the illumination and without illumination groups, respectively, while the control group was injected with PBS. After administration, the tumors of the control and illumination groups were irradiated by an $808 \mathrm{~nm}$ laser for 8 minutes while the mice in the no illumination group were not irradiated. Tumor volume $(V)$ was measured daily to observe dynamic changes in tumor growth and calculated according to the formula: $V\left(\mathrm{~mm}^{3}\right)=$ length $\times$ width $^{2} \times 0.5$. The treatment process was conducted for twenty days, and the tumor volume and body weight of the mice were recorded every two days. At the end of treatment, all the nude mice were sacrificed and the tumor tissues were removed and measured for histopathological assay. Some major organs (heart, liver, spleen, lung, and kidney) were removed for histopathological examination to evaluate drug toxicity.

\section{In vivo imaging}

$100 \mu \mathrm{L}$ BDPTPA NPs $\left(100 \mu \mathrm{g} \mathrm{mL}^{-1}\right)$ solution in PBS was administered into nude mice through tail intravenous injection. At different time points after tail intravenous injection, in vivo fluorescence images were recorded using an Endra Nexus128 small animal imaging system. The temperature was also monitored using an FLIR thermal camera under irradiation of an $808 \mathrm{~nm}$ laser for $10 \mathrm{~min}, 6 \mathrm{~h}$ post-injection. The mice injected with saline were evaluated as a control.

\section{Pharmacokinetic study}

Twelve Sprague-Dawley rats (six males and six females, $220 \pm$ $10.0 \mathrm{~g}$ ) were obtained from the Animal Center of Nanjing Medical University (NJMU, Nanjing, China). The animals were housed under standard conditions and had free access to food and water. This animal study was reviewed and approved by the Animal Ethical Committee of Nanjing Tech University.

Twelve rats were given BDPTPA NPs and BDPTPA molecular solution dissolved in saline containing $10 \%$ DMSO at the same dose of $5 \mathrm{mg} \mathrm{kg}^{-1}$ via tail vein injection. Blood samples $(0.2 \mathrm{~mL})$ were collected in heparinized Eppendorf tubes from the ophthalmic venous plexus at 0 (pre-dose), 0.083, 0.25, 0.5, 1, 2, 4, 6, 8, 12 and $24 \mathrm{~h}$ after intravenous (i.v.) administration. Plasma was separated by centrifuging the blood at $3000 \times g$ for $10 \mathrm{~min}$ at $4{ }^{\circ} \mathrm{C}$ and stored at $-70{ }^{\circ} \mathrm{C}$ until analysis.

The standard stock solutions of BDPTPA and BDPTPA NPs were accurately prepared in DMSO and PBS solutions. A series of standard working solutions for BDPTPA was prepared by diluting the stock solution with DMSO to concentrations in the range of $12.5-500 \mu \mathrm{g} \mathrm{mL}{ }^{-1}$, while the working solutions for BDPTPA NPs were diluted with PBS in the same range. Subsequently, the calibration standards were prepared by spiking
$20 \mu \mathrm{L}$ BDPTPA or BDPTPA NPs into $180 \mu \mathrm{L}$ blank rat plasma at concentrations of $1.25,2.5,5,10,20$, and $50 \mu \mathrm{g} \mathrm{mL} \mathrm{m}^{-1}$. The standard curve samples and the rat plasma samples were transferred to a micro cuvette and analyzed by an ultraviolet spectrophotometer.

The pharmacokinetic parameters were calculated by a noncompartmental method using DAS 3.0 software (Mathematical Pharmacology Professional Committee of China, Shanghai, China). The area under the curve (AUC) from zero to the last measurable plasma concentration point $\left(\mathrm{AUC}_{0-t}\right)$, $\mathrm{AUC}$ from zero to infinity $\left(\mathrm{AUC}_{0-\infty}\right)$, the elimination rate constant $(K)$, the terminal elimination half-life $\left(T_{1 / 2}\right)$, mean residence time (MRT), and systemic clearance (CL) were calculated by the software.

\section{Results and discussion}

\section{Synthesis and characterization of BDPTPA and NPs}

The synthetic procedure of BDPTPA is proposed in the ESI $\dagger$ (Fig. S1). All the intermediates and products have been fully structurally characterized by ${ }^{1} \mathrm{H}$ NMR (Fig. S2, ESI $\dagger$ ), ${ }^{13} \mathrm{C}$ NMR (Fig. S3, ESI $\dagger$ ) and mass spectrometry (Fig. S4, ESI $\dagger$ ). For ${ }^{1} \mathrm{H}$ NMR $\left(\mathrm{CDCl}_{3}, 400 \mathrm{MHz}\right): \delta$ (ppm) 7.61-7.54 (2H, d), 7.48$7.43(4 \mathrm{H}, \mathrm{d}), 7.31-7.28$ (2H, d), $7.25-7.22$ (3H, d), 7.21-7.15 (2H, d), 7.14-7.09 (9H, d), 7.09-7.04 (6H, m), 7.04-6.98 (5H, d), 6.79-6.76 (1H, d), $6.63(2 \mathrm{H}, \mathrm{s}), 1.74(6 \mathrm{H}, \mathrm{s}) .{ }^{13} \mathrm{C}$ NMR (75 MHz, $\left.\mathrm{CDCl}_{3}\right): \delta 153.15,148.67,147.05,141.52,136.18,130.24,129.39$, 128.67, 125.18, 123.49, 122.34, 118.06, 117.23, 31.55, 30.13, 29.68, 14.23. MS (ESI): calcd $\mathrm{m} / z=918.2$; found $\mathrm{m} / z=921.7$.

Since the compound can be hardly dissolved in water, the water-soluble BDPTPA NPs were prepared through a simple re-precipitation method. In general, $10 \mathrm{mg}$ of BDPTPA was dissolved in THF, and $200 \mu \mathrm{L}$ of such solution was injected into $10 \mathrm{~mL}$ distilled water with stirring. After being purged with nitrogen for $20 \mathrm{~min}$ to drive the THF off, the concentration of the obtained solution is $200 \mu \mathrm{g} \mathrm{mL}{ }^{-1}$.

As shown in Fig. 1a, BDPTPA NPs present a broad absorption range and the absorption peak was observed at $750 \mathrm{~nm}$, while BDPTPA in DCM shows absorption with maximum intensity of $720 \mathrm{~nm}$, which shows a red-shift of $30 \mathrm{~nm}$ caused by aggregation into nanoparticles, and BDPTPA show emission with maximum intensity at $780 \mathrm{~nm}$ (Fig. 1b), while a red shift of $40 \mathrm{~nm}$ was found for its nanoparticles. BDPTPA shows emissions with maximum intensity at $790 \mathrm{~nm}$, while a red shift of $30 \mathrm{~nm}$ was found for its nanoparticles. Then, the morphology and diameter of the nanoparticles was characterized by a transmission electron microscope (TEM) and dynamic light scattering (DLS). As shown in Fig. 1e, the morphology of the nanoparticles showed well defined spherical nanostructures, and the average diameter distribution was from approximately 40 to $160 \mathrm{~nm}$. In order to achieve deep tissue penetration in the NIR window, the BDPTPA NPs were used in the subsequent experiments.

A high singlet oxygen quantum yield (QY) is fundamental to PDT efficacy. 1,3-Diphenylisobenzofuran (DPBF) was used as a 

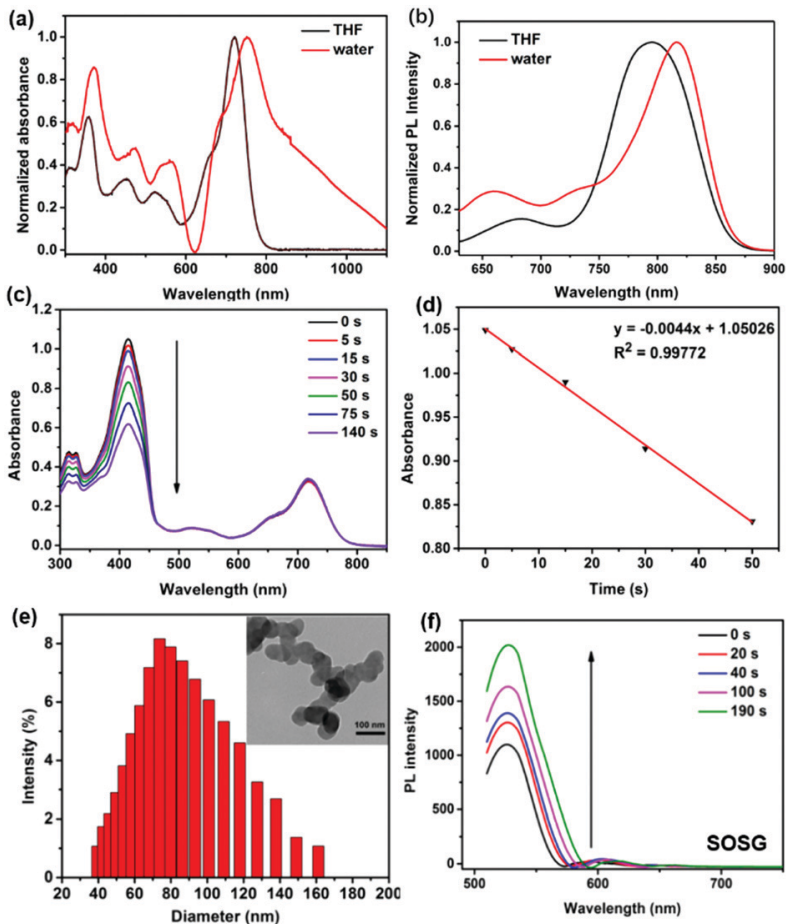

Fig. 1 Normalized (a) absorption and (b) emission spectra of BDPTPA in THF and NPs in water. (c) The degradation of DPBF in the presence of BDPTPA in DCM and $660 \mathrm{~nm}$ laser irradiation. (d) Linear fitting of the absorption and the irradiation time. (e) The DLS size distribution of the BDPTPA NPs. Inset: A TEM image of BDPTPA NPs. (f) Fluorescence enhancement of SOSG with laser irradiation $\left(808 \mathrm{~nm}, 0.5 \mathrm{~W} \mathrm{~cm}^{-2}\right)$.

probe to measure the singlet oxygen QY of BDPTPA in DCM, the absorption of DPBF was recorded under irradiation for different times. With methylene blue (MB) as the standard substance $\left(\Phi_{\Delta}=0.57\right.$ in DCM) (Fig. S5, ESI $\left.\dagger\right)$, the singlet oxygen QYs were calculated according to the literature ${ }^{47}$ and demonstrated an outstanding singlet oxygen generation efficiency. As shown in Fig. 1c and d, in the presence of BDPTPA, the DPBF degrades at a high speed, compared with that of MB. The calculated ${ }^{1} \mathrm{O}_{2}$ QY of BDPTPA is $35.2 \%$. At the same time, SOSG (singlet oxygen sensor green) was used to evaluate the singlet oxygen of BDPTPA NPs in PBS solution. Fig. If shows that the fluorescence intensity of SOSG has been greatly enhanced with laser irradiation, suggesting the high singlet generation ability of BDPTPA NPs.

Furthermore, the near-infrared absorption indicates that the BDPTPA NPs also possess high photothermal conversion ability. The photothermal conversion ability of BDPTPA NPs was calculated by recording the temperature elevation with irradiation in the presence of BDPTPA NPs and a cooling process without irradiation. As illustrated in Fig. 2a, a temperature increase of $28.7{ }^{\circ} \mathrm{C}$ could be observed with low power laser irradiation ( $808 \mathrm{~nm}, 0.5 \mathrm{~W} \mathrm{~cm}^{-2}$ ) while a negligible one was observed for water, of only $2.8{ }^{\circ} \mathrm{C}$, indicating the excellent photothermal conversion ability of such NPs. According to the equation described in the previous report, ${ }^{48}$ the photothermal conversion efficiency $(\eta)$ was calculated to be $52.6 \%$.
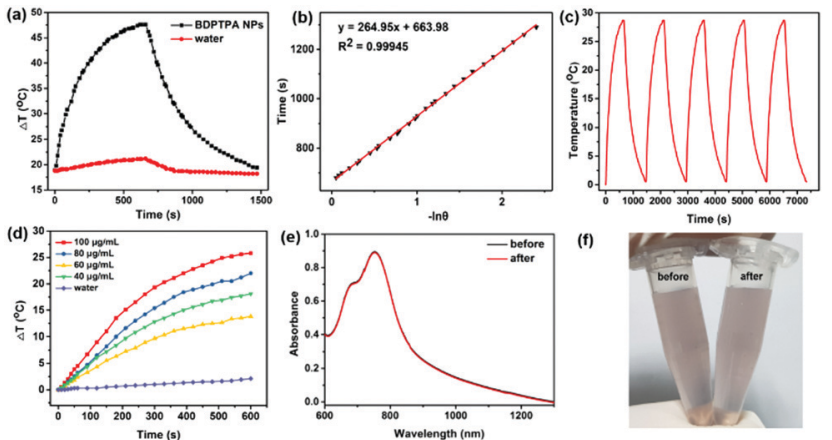

Fig. 2 (a) Temperature increase of water and BDPTPA NPs with laser irradiation (water was irradiated as a control). (b) Linear fitting of $-\ln \theta$ and time in the cooling curve. (c) The heating curve of the BDPTPA NPs at a concentration of $100 \mathrm{mg} \mathrm{mL}^{-1}$ during five cycles. (d) The heating curves of the BDPTPA NPs with different concentrations. (e and f) The absorbance spectra and color of the BDPTPA NPs before/after laser irradiation.

Fig. 2e shows the light-to-heat cycling stability of the BDPTPA NPs. There is no decrease in the temperature elevation after five cycles, and the color of the BDPTPA NPs has no changes before and after irradiation for five cycles (Fig. 2c and f); all these results reveal that the BDPTPA NPs have good photothermal stability. In addition, BDPTPA NPs with different concentrations $\left(20,40,60,80 \mu \mathrm{g} \mathrm{mL}^{-1}\right)$ were used to examine the photothermal conversion ability under the same conditions; as shown in Fig. 2d, the temperature increase of the BDPTPA NPs is obviously concentration-dependent under laser irradiation.

\section{BDPTPA induced apoptosis in human osteosarcoma cells}

To validate the synergistic phototherapeutic effects of BDPTPA NPs, we evaluated the inhibitory effect of BDPTPA NPs on the cell viability of human osteosarcoma cells including HOS, U-2OS, MG-63 and 143B cells at different concentrations. After treatment of BDPTPA NPs for $24 \mathrm{~h}$, MTT assay shows that the $\mathrm{IC}_{50}$ (the concentration of drug inhibiting $50 \%$ of cells) values of HOS, U-2OS, MG-63 and 143B cells were 4.38, 5.729, 5.862 and $3.996 \mu \mathrm{g} \mathrm{mL} \mathrm{m}^{-1}$ respectively (Fig. 3a-d). In addition, the group incubated with the nanoparticles without irradiation have low dark toxicity. At the same time, the normal human cells including HEK-293 (Human Embryonic Kidney 293 cells), HUVEC (Human Umbilical Vein Endothelial Cells), L02 (Human L02 hepatocytes) and BEAS-2B (Human Bronchial Epithelial Cells) were used to evaluate the dark toxicity, and the results also show that the BDPTPA NPs have low dark toxicity to normal cells (Fig. S6, ESI $\dagger$ ).

And then Annexin V-FITC/PI double staining assay was used to confirm the pro-apoptotic effect of BDPTPA NPs. Compared with a control group, the results demonstrated that the apoptotic rates of 143B cells in the illumination group were significantly increased after treatment with BDPTPA NPs $\left(5 \mu \mathrm{g} \mathrm{mL}^{-1}\right)$, while the apoptotic rate of the without illumination group was similar to that of the control group (Fig. 3e), which demonstrates that BDPTPA NPs can induce typical apoptosis in human osteosarcoma cells under irradiation. 

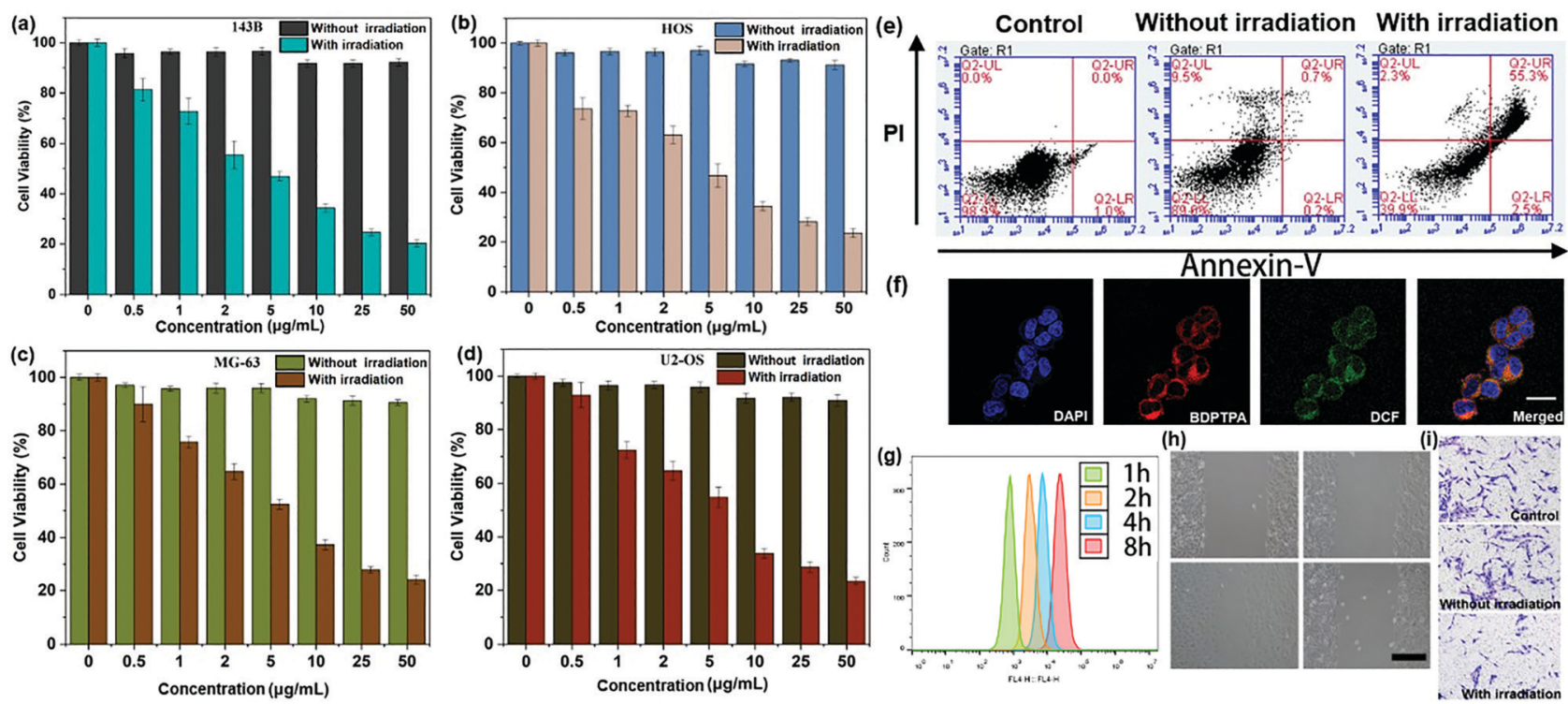

(h)

Fig. 3 MTT assay of BDPTPA NPs with different concentrations on four osteosarcoma cells. (a) 143B; (b) HOS; (c) MG-63; (d) U2-OS. (e) The apoptotic rates of 143B cells induced by BDPTPA NPs were detected by Annexin V/PI double-staining assay. (f) Cellular uptake of BDPTPA NPs and ROS generation with DCF-DA as a probe. Scale bar: $10 \mu \mathrm{m}$. (g) Cellular uptake by flow cytometry fluorescence enhancement at different times. (h) $143 \mathrm{~B}$ cell migration in the scratch-wound healing assay. Scale bar: $100 \mu \mathrm{m}$. (i) The transwell migration assay of 143B cells.

\section{In vitro cell migration and invasion of osteosarcoma cells}

The property of inhibiting cell migration is important for a photosensitizer, because osteosarcoma tumors are highly metastatic in vivo. Firstly, the "wound-healing" assays were used to investigate the effect of BDPTPA NPs on cell migration. As shown in Fig. 3g, it is obvious to observe that 143B cells in the control group moved and filled in the open gap at $24 \mathrm{~h}$ after wounding, while BDPTPA NPs treatment with illumination dramatically suppressed wound closure even at a low concentration $\left(1 \mu \mathrm{g} \mathrm{mL}^{-1}\right)$. These results show that BDPTPA NPs can effectively inhibit the migration of osteosarcoma cells, which might have the potential of inhibiting tumor metastasis in vivo.

And then Transwell experiments were used to verify the ability of inhibiting cell invasion under the treatment of BDPTPA NPs (Fig. 3h). These results showed that BDPTPA NPs could inhibit the migration and invasion of osteosarcoma cells in vitro without cytotoxicity, demonstrating that BDPTPA NPs could be a potential and multiple functional agent for treating human osteosarcoma tumors.

\section{Cellular uptake and ROS generation in vitro}

A confocal living cell imaging system was used to investigate the cellular uptake behaviors of BDPTPA NPs. The cellular uptake of BDPTPA NPs is shown in Fig. 3f. A high intracellular fluorescence intensity in the cytoplasmic matrix can be observed, indicating that the BDPTPA NPs can be used for cell imaging in vitro. Further flow cytometry confirms the uptake of BDPTPA NPs in 143B cells due to the time dependent fluorescence enhancement.

$2^{\prime}, 7^{\prime}$-Dichlorofluorescein diacetate (DCF-DA) was used to investigate the ROS generation of BDPTPA NPs in cells. As shown in Fig. 3f, strong green fluorescence can be observed, indicating that BDPTPA NPs are able to generate strong singlet oxygen under irradiation in vitro.

\section{In vivo fluorescence imaging guided phototherapy}

Fig. 4a shows the fluorescence images of tumor tissues at different times after the tail vein injection of BDPTPA NPs $\left(100 \mu \mathrm{g} \mathrm{mL} \mathrm{m}^{-1}, 100 \mu \mathrm{L}\right)$. The fluorescence signals of the tumors increased rapidly and maintained a high level from 1 to $24 \mathrm{~h}$ after injection, suggesting that BDPTPA NPs can be effectively accumulated at tumor sites because of the enhanced permeability and retention (EPR) effect. The results show that after $6 \mathrm{~h}$ injection, the fluorescence intensity reached a maximum level, suggesting that 6 hour may be suitable for PDT after administration. Furthermore, after $24 \mathrm{~h}$ injection, the fluorescence signal of the tumor was still at a high level, indicating that BDPTPA NPs can be used as a long-term fluorescence imaging agent. Finally, the mice were sacrificed and the biodistribution shows that BDPTPA NPs mainly stay in the tumor, liver and kidneys (Fig. 4a and b).

\section{Pharmacokinetic studies in rats}

The sensitive and specific ultraviolet spectrophotometer was applied in the pharmacokinetic study of BDPTPA and BDPTPA NPs after intravenous administration. The mean plasma concentration-time profiles of BDPTPA and BDPTPA NPs are shown in Fig. 5a. The major pharmacokinetic parameters were calculated by a non-compartmental model and are presented in Table 1. The values of the $\mathrm{AUC}_{(0-t)} / \mathrm{AUC}_{(0-\infty)}$ were more than $80 \%$ suggesting that the blood collection time point was suitable for the pharmacokinetic studies. The data showed that the BDPTPA eliminated much more quickly than BDPTPA NPs, the terminal elimination half-life $\left(T_{1 / 2}\right)$ was $1.727 \pm 0.415$ and 

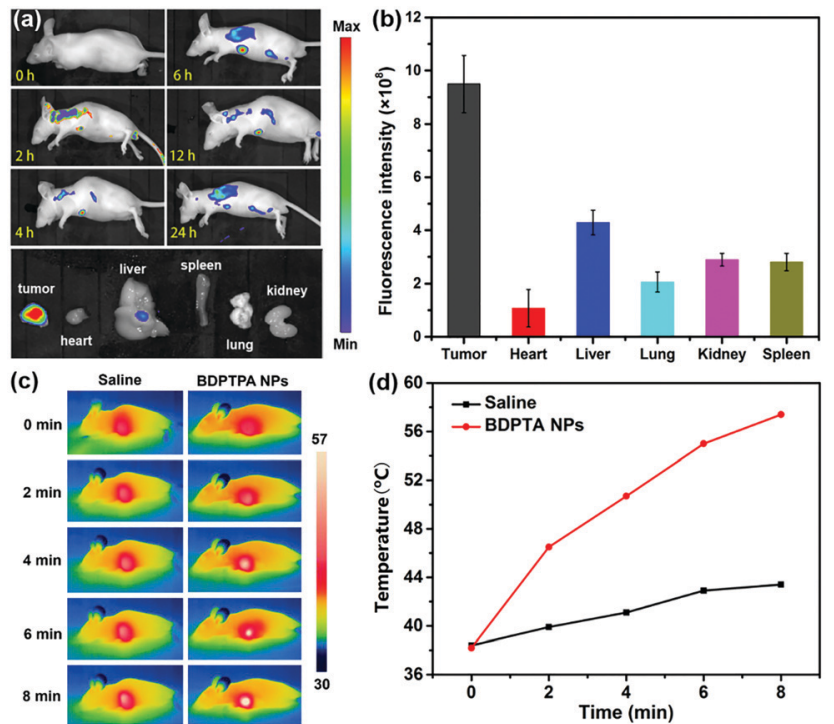

Fig. 4 (a) In vivo time dependent fluorescence imaging and biodistribution of BDPTPA NPs in the tumor, heart, liver, spleen, lungs and kidneys after injection for $24 \mathrm{~h}$. (b) Fluorescence intensity of the tumor, heart, liver, lungs, spleen, and kidneys. (c) In vivo photothermal imaging of the nude mice after injection with saline or BDPTPA NPs under laser irradiation. (d) Temperature increase of the group injected with saline or BDPTPA NPs under laser irradiation.

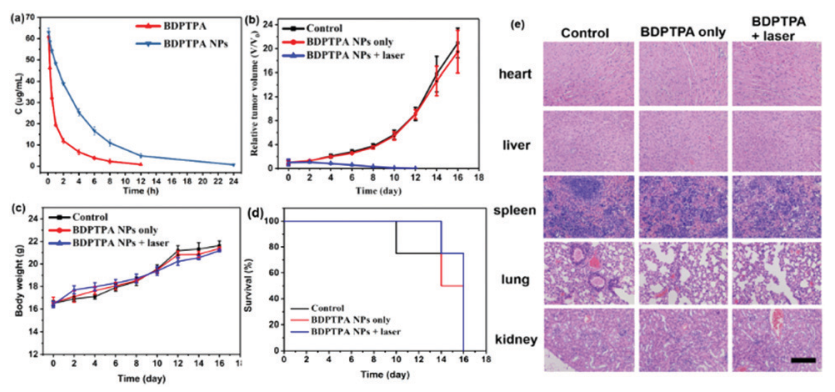

Fig. 5 (a) Mean plasma concentration-time curves of BDPTPA and BDPTPA NPs after a single intravenous administration at a dose of $5 \mathrm{mg} \mathrm{kg}^{-1}$ in rats. (b) Relative tumor volume. (c) Body weight change of three groups. (d) Survival of the mice during treatment. (e) H\&E stained images of the heart, liver, spleen, lungs, and kidneys of three groups, respectively. Scale bar: $100 \mu \mathrm{m}$.

$5.639 \pm 0.37 \mathrm{~h}$ for BDPTPA and BDPTPA NPs, respectively. The CLz of BDPTPA was $0.053 \pm 0.003 \mathrm{~L} \mathrm{~h}^{-1} \mathrm{~kg}^{-1}$ while the value of BDPTPA NPs was $0.016 \pm 0.001 \mathrm{~L} \mathrm{~h}^{-1} \mathrm{~kg}^{-1}$, which also indicated that the BDPTPA NPs eliminated slower than BDPTPA in rats, and all the results show that the BDPTPA NPs could extend the residence time in rats and promote its treatment effects.

\section{In vivo photothermal imaging and phototherapy}

To further investigate the PDT and PTT synergistic therapeutic efficacy of BDPTPA NPs in vivo, 12 nude mice bearing osteosarcoma tumors were used in this study. As shown in Fig. 4c, under irradiation, the tumor surface temperature increased
Table 1 Non-compartmental pharmacokinetic parameters of BDPTPA and BDPTPA NPs in rat plasma after a single intravenous administration at a dose of $5 \mathrm{mg} \mathrm{kg}^{-1}(n=6)$

\begin{tabular}{|c|c|c|c|}
\hline Parameter & Unit & BDPTPA in DMSO (10\%) & BDPTPA NPs \\
\hline$T_{1 / 2}$ & $\mathrm{H}$ & $1.727 \pm 0.415$ & $5.639 \pm 0.37$ \\
\hline $\operatorname{AUC}_{(0-t)}$ & $\mathrm{mg} \mathrm{L}^{-1} \mathrm{~h}$ & $93.744 \pm 5.297$ & $298.588 \pm 12.477$ \\
\hline $\operatorname{AUC}_{(0-\infty)}$ & $\mathrm{mg} \mathrm{L}^{-1} \mathrm{~h}$ & $94.586 \pm 5.081$ & $307.545 \pm 14.671$ \\
\hline $\mathrm{MRT}_{(0-t)}$ & $\mathrm{H}$ & $2.274 \pm 0.415$ & $4.717 \pm 0.161$ \\
\hline $\mathrm{CL}_{\mathrm{z}}$ & $\mathrm{L} \mathrm{h}^{-1} \mathrm{~kg}^{-1}$ & $0.053 \pm 0.003$ & $0.016 \pm 0.001$ \\
\hline$V_{\mathrm{z}}$ & $\mathrm{L} \mathrm{kg}^{-1}$ & $0.132 \pm 0.035$ & $0.132 \pm 0.003$ \\
\hline
\end{tabular}

$T_{1 / 2}$ : terminal elimination half-life; $\mathrm{AUC}_{0-t}$ : the area under the curve from zero to the last measurable plasma concentration point; $\mathrm{AUC}_{0-\infty}$ : the area under the curve from zero to infinity; $\mathrm{MRT}_{(0-t)}$ : mean residence time; $\mathrm{CL}_{z}$ : systematic clearance; $V_{\mathrm{z}}$ : apparent volume of distribution.

rapidly with 8 min compared with the control group. Fig. 5b shows that the tumor volume of the control and the without illumination group increase at a high speed. While after the irradiation treatment, the tumor volume was not significantly increased in the illumination group; after treatment six times, the tumor of the illumination group even disappears at the end of the therapy process, and all the mice were still raised for another 6 days, and no obvious tumors were observed. All of these results indicate that BDPTPA NPs have high phototoxicity and efficiency for tumor treatment. The tumor volume and body weight were recorded every two days.

Though BDPTPA NPs inhibited the growth of tumors in vivo, their potential toxicity must be assessed comprehensively. During the treatment process, no significant difference between the body weight of the mice in the three groups was observed (Fig. 5c), which indicates the low dark toxicity of BDPTPA NPs. The cured mice in the illumination group are shown in Fig. S7 (ESI $\dagger$ ).

After the treatment, all the mice were sacrificed and the tumors were collected as well as the normal organs, including heart, liver, spleen, lungs, and kidneys. The trend of the tumor is shown in Fig. 5d. According to the hematoxylin and eosin (H\&E)-stained images, we also found no obvious change in normal organs between control and BDPTPA NPs treated groups (Fig. 5e). The results indicated that BDPTPA NPs exerted anti-tumor activity without any toxicity in vivo. The blood index, liver function and renal function of the mice injected with BDPTPA NPs are the same as those in the control group (Table S, ESI $\dagger$ ). The results indicated that BDPTPA NPs can inhibit tumor growth effectively without damaging the normal organs, suggesting their good bio-compatibility. ${ }^{49-54}$

\section{Conclusions}

In conclusion, BDPTPA with both photodynamic and photothermal effects was designed and synthesized. The results show that BDPTPA presents high singlet oxygen generation efficiency $(35.2 \%)$ as well as high photothermal conversion efficiency (52.6\%). In vitro experiments suggest that BDPTPA NPs could induce significant apoptosis of osteosarcoma cells with irradiation, while they have no effect on the viability of normal cells 
under dark conditions. In addition, such NPs can inhibit the migration of osteosarcoma cells, confirmed by the cell migration and transwell experiments. In in vivo experiments, the BDPTPA NPs could accumulated in tumor tissues by the EPR effect and inhibit tumor growth without any side effects in nude mice. Moreover, the BDPTPA NPs have a good pharmacokinetic characteristic in contrast to BDPTPA. Both in vitro and in vivo experiments indicate that the BDPTPA NPs have an excellent photo toxicity, low dark toxicity and good biocompatibility. Therefore, BDPTPA is a promising multi-functional agent for the treatment of osteosarcoma.

\section{Conflicts of interest}

The authors have no conflict of interest to declare.

\section{Acknowledgements}

This work was supported by the National Natural Science Foundation of China (No. 81373478 and 81703556), the Natural Science Foundation of Jiangsu Province (No. BK20171024), the Jiangsu Synergetic Innovation Center for Advanced BioManufacture, the Key University Science Research Project of Jiangsu Province (15KJA430006), the QingLan Project and the Program for Innovative Research Team in University of Jiangsu Province. We would like to add the no. of the funding of the Jiangsu Synergetic Innovation Center for Advanced BioManufacture (No. XTD1819).

\section{Notes and references}

1 L. Mirabello, R. J. Troisi and S. A. Savage, Int. J. Cancer, 2009, 125, 229-234.

2 S. S. Bielack, S. Hecker-Nolting, C. Blattmann and L. Kager, F1000Research, 2016, 5, 2767.

3 S. S. Bielack, B. Kempf-Bielack, G. Delling, G. U. Exner, S. Flege, K. Helmke, R. Kotz, M. Salzer-Kuntschik, M. Werner, W. Winkelmann, A. Zoubek, H. Jurgens and K. Winkler, J. Clin. Oncol., 2002, 20, 776-790.

4 S. Bielack, B. Kempf-Bielack, T. Von Kalle, R. Schwarz, T. Wirth, L. Kager and J. Whelan, Minerva Pediatr., 2013, 65, 125-148.

5 S. Ferrari and M. Serra, Expert Opin. Pharmacother., 2015, 16, 2727-2736.

6 L. Kager, A. Zoubek, U. Potschger, U. Kastner, S. Flege, B. Kempf-Bielack, D. Branscheid, R. Kotz, M. Salzer-Kuntschik, W. Winkelmann, G. Jundt, H. Kabisch, P. Reichardt, H. Jurgens, H. Gadner, S. S. Bielack and G. Cooperative German-AustrianSwiss Osteosarcoma Study, J. Clin. Oncol., 2003, 21, 2011-2018.

7 M. E. Anderson, Orthopedic Clinics of North America, 2016, vol. 47, pp. 283-292.

8 A. Longhi, C. Errani, M. De Paolis, M. Mercuri and G. Bacci, Cancer Treat. Rev., 2006, 32, 423-436.

9 H. Wafa and R. J. Grimer, Expert Rev. Anticancer Ther., 2006, 6, 239-248.
10 K. Ando, M. F. Heymann, V. Stresing, K. Mori, F. Redini and D. Heymann, Cancers, 2013, 5, 591-616.

11 P. Agostinis, K. Berg, K. A. Cengel, T. H. Foster, A. W. Girotti, S. O. Gollnick, S. M. Hahn, M. R. Hamblin, A. Juzeniene, D. Kessel, M. Korbelik, J. Moan, P. Mroz, D. Nowis, J. Piette, B. C. Wilson and J. Golab, Ca-Cancer J. Clin., 2011, 61, 250-281.

12 A. Matsunobu, R. Imai, T. Kamada, T. Imaizumi, H. Tsuji, H. Tsujii, Y. Shioyama, H. Honda, S. Tatezaki and W. G. B. S. T. Sarco, Cancer, 2012, 118, 4555-4563.

13 D. Carrle and S. S. Bielack, Int. Orthop., 2006, 30, 445-451.

14 G. Rosen, B. Caparros, A. G. Huvos, C. Kosloff, A. Nirenberg, A. Cacavio, R. C. Marcove, J. M. Lane, B. Mehta and C. Urban, Cancer, 1982, 49, 1221-1230.

15 R. Luksch, D. Perotti, G. Cefalo, C. G. Passerini, M. Massimino, F. Spreafico, M. Casanova, A. Ferrari, M. Terenziani, D. Polastri, F. Gambirasio, M. Podda, F. Bozzi, F. Ravagnani, G. Parmiani and F. F. Bellani, Tumori, 2003, 89, 263-268.

16 C. Liebau, C. Roesel, S. Schmidt, C. Karreman, J. B. Prisack, H. Bojar, H. Merk, N. Wolfram and A. W. Baltzer, Anticancer Res., 2004, 24, 2861-2867.

17 S. Yanase, J. Nomura, Y. Matsumura, Y. Watanabe and T. Tagawa, Photomed. Laser Surg., 2009, 27, 791-797.

18 A. Konski, Cancer, 2010, 116, 3754-3755.

19 L. L. Sun, Y. J. Li, H. Y. Li, J. Zhang, B. H. Li and Z. M. Ye, Clin. Ther., 2014, 36, 567-578.

20 M. Ethirajan, Y. Chen, P. Joshi and R. K. Pandey, Chem. Soc. Rev., 2011, 40, 340-362.

21 L. Lin, L. Xiong, Y. Wen, S. Lei, X. Deng, Z. Liu, W. Chen and X. Miao, J. Biomed. Nanotechnol., 2015, 11, 531-554.

22 T. G. S. Denis and M. R. Hamblin, Bioanalysis, 2013, 5, 1099-1114.

23 L. Cheng, C. Wang, L. Z. Feng, K. Yang and Z. Liu, Chem. Rev., 2014, 114, 10869-10939.

24 Z. Zhen, W. Tang, Y. J. Chuang, T. Todd, W. Zhang, X. Lin, G. Niu, G. Liu, L. Wang, Z. Pan, X. Chen and J. Xie, ACS Nano, 2014, 8, 6004-6013.

25 C. S. Jin, J. F. Lovell, J. Chen and G. Zheng, ACS Nano, 2013, 7, 2541-2550.

26 J. P. Wang, R. Yan, F. Guo, M. Yu, F. P. Tan and N. Li, Nanotechnology, 2016, 27, 285102.

27 A. E. O'Connor, W. M. Gallagher and A. T. Byrne, Photochem. Photobiol., 2009, 85, 1053-1074.

28 F. van Leeuwen-vanZaane, H. S. de Bruijn, A. van der Ploegvan den Heuvel, H. J. M. C. Sterenborg and D. J. Robinson, Photodiagn. Photodyn. Ther., 2014, 11, 71-81.

29 R. Weijer, M. Broekgaarden, M. Krekorian, L. K. Alles, A. C. van Wijk, C. Mackaaij, J. Verheij, A. C. van der Wal, T. M. van Gulik, G. Storm and M. Heger, Oncotarget, 2016, 7, 3331-3346.

30 Z. P. Zhen, W. Tang, Y. J. Chuang, T. Todd, W. Z. Zhang, X. Lin, G. Niu, G. Liu, L. C. Wang, Z. W. Pan, X. Y. Chen and J. Xie, ACS Nano, 2014, 8, 6004-6013.

31 D. de Melo-Diogo, C. Pais-Silva, D. R. Dias, A. F. Moreira and I. J. Correia, Adv. Healthcare Mater., 2017, 6, 1700073. 
32 U. Lindner, N. Lawrentschuk, R. A. Weersink, S. R. Davidson, O. Raz, E. Hlasny, D. L. Langer, M. R. Gertner, T. Van der Kwast, M. A. Haider and J. Trachtenberg, Eur. Urol., 2010, 57, 1111-1114.

33 K. Ahrar, A. Gowda, S. Javadi, A. Borne, M. Fox, R. McNichols, J. U. Ahrar, C. Stephens and R. J. Stafford, J. Vasc. Intervent. Radiol., 2010, 21, 555-561.

34 C. Fotia, S. Avnet, K. Kusuzaki, L. Roncuzzi and N. Baldini, Curr. Pharm. Des., 2015, 21, 4088-4094.

35 H. Satonaka, K. Kusuzaki, K. Akeda, M. Tsujii, T. Iino, T. Uemura, T. Matsubara, T. Nakamura, K. Asanuma, A. Matsumine and A. Sudo, Anticancer Res., 2011, 31, 4163-4168.

36 S. Yanase, J. Nomura, Y. Matsumura, T. Nagata, T. Fujii and T. Tagawa, Int. J. Oncol., 2006, 29, 365-373.

37 I. Coupienne, G. Fettweis and J. Piette, Lasers Surg. Med., 2011, 43, 557-564.

38 D. Meier, C. Campanile, S. M. Botter, W. Born and B. Fuchs, J. Visualized Exp., 2014, e51213, DOI: 10.3791/51213.

39 M. X. Sun, C. H. Zhou, H. Zeng, N. Puebla-Osorio, E. Damiani, J. Chen, H. S. Wang, G. D. Li, F. Yin, L. C. Shan, D. Q. Zuo, Y. X. Liao, Z. Y. Wang, L. P. Zheng, Y. Q. Hua and Z. D. Cai, Photochem. Photobiol., 2015, 91, 533-544.

40 T. Matsubara, K. Kusuzaki, A. Matsumine, H. Satonaka, K. Shintani, T. Nakamura and A. Uchida, In Vivo, 2008, 22, 297-303.

41 H. J. Wories, J. H. Koek, G. Lodder, J. Lugtenburg, R. Fokkens, O. Driessen and G. R. Mohn, Recl. Trav. Chim. Pays-Bas, 1985, 104, 288-291.

42 J. Chen, A. Burghart, A. Derecskei-Kovacs and K. Burgess, J. Org. Chem., 2000, 65, 2900-2906.
43 J. Chen, A. Burghart, C. W. Wan, L. Thia, C. Ortiz, J. Reibenspies and K. Burgess, Tetrahedron Lett., 2000, 41, 2303-2307.

44 K. Rurack, M. Kollmannsberger, U. Resch-Genger and J. Daub, J. Am. Chem. Soc., 2000, 122, 968-969.

45 X. Qi, E. J. Jun, L. Xu, S. J. Kim, J. S. J. Hong, Y. J. Yoon and J. Y. Yoon, J. Org. Chem., 2006, 71, 2881-2884.

46 M. Tasior, J. Murtagh, D. O. Frimannsson, S. O. McDonnell and D. F. O'Shea, Org. Biomol. Chem., 2010, 8, 522-525.

47 H. X. Shi, W. C. Sun, C. B. Liu, G. Y. Gu, B. Ma, W. L. Si, N. N. Fu, Q. Zhang, W. Huang and X. C. Dong, J. Mater. Chem. B, 2016, 4, 113-120.

48 S. Ghosh, T. Avellini, A. Petrelli, I. Kriegel, R. Gaspari, G. Almeida, G. Bertoni, A. Cavalli, F. Scotognella, T. Pellegrino and L. Manna, Chem. Mater., 2016, 28, 4848-4858.

49 Z. Yang, Y. Dai, L. Shan, Z. Shen, Z. Wang, B. C. Yung, O. Jacobson, Y. Liu, W. Tang, S. Wang, L. Lin, G. Niu, P. Huang and X. Chen, Nanoscale Horiz., 2019, 4, 426-433.

50 Z. Yang, W. Fan, W. Tang, Z. Shen, Y. Dai, J. Song, Z. Wang, Y. Liu, L. Lin, L. Shan, Y. Liu, O. Jacobson, P. Rong, W. Wang and X. Chen, Angew. Chem., Int. Ed., 2018, 130, 14297-14301.

51 J. Yang, X. Q. Gu, W. T. Su, X. Y. Hao, Y. J. Shi, L. Y. Zhao, D. F. Zou, G. W. Yang, Q. Y. Li and J. H. Zou, Mater. Chem. Front., 2018, 2, 1842-1846.

52 Z. Yang, Y. Dai, C. Yin, Q. Fan, W. Zhang, J. Song, G. Yu, W. Tang, W. Fan, B. C. Yung, J. Li, X. Li, X. Li, Y. Tang, W. Huang, J. Song and X. Chen, Adv. Mater., 2018, 30, 1707509.

53 Z. Yang, R. Tian, J. Wu, Q. Fan, B. C. Yung, G. Niu, O. Jacobson, Z. Wang, G. Liu, G. Yu, W. Huang, J. Song and X. Chen, ACS Nano, 2017, 11, 4247-4255.

54 Z. Yang, J. Song, Y. Dai, J. Chen, F. Wang, L. Lin, Y. Liu, F. Zhang, G. Yu, Z. Zhou, W. Fan, W. Huang, Q. Fan and X. Chen, Theranostics, 2017, 7, 2177. 